\title{
Incidence and prognosis of congenital aortic valve stenosis in Liverpool (1960-1990)
}

\author{
D J Kitchiner, M Jackson, K Walsh, I Peart, R Arnold
}

Heart Clinic and

Health, Royal

Liverpool Children's

Hospital, Liverpool

D J Kitchiner

$M$ Jackson

K Walsh

I Peart

R Arnold

Correspondence to

Dr D J Kitchiner,

Heart Clinic, Royal

Liverpool Children's

Hospital, Eaton Road,

Liverpool L12 2AP.

Accepted for publication

15 July 1992.

\begin{abstract}
Objective-To determine the incidence and prognosis of congenital aortic valve stenosis in the five Health Districts of Liverpool that make up the Merseyside area.
\end{abstract}

Design-The records of the Liverpool Congenital Malformations Registry and the Royal Liverpool Children's Hospital identified 239 patients (155 male, 84 female) born with aortic valve stenosis between 1960 and 1990. Patients were traced to assess the severity of stenosis at follow up. Information on the severity at presentation and all subsequent events was obtained.

Results-Congenital aortic valve stenosis occurred in $5.7 \%$ of patients with congenital heart disease born in the Merseyside area. The median age at presentation was 16 months (range 0-20 years). Stenosis was mild at presentation in 145 patients, moderate in 33, severe in one and critical in 21 and 39 had a bicuspid valve without stenosis. Additional cardiac lesions were significantly more common in children presenting under one year of age and in those with critical stenosis. The median duration of follow up was $9 \cdot 2$ years (range 1-28 years) and seven patients were lost to follow up. 81 operations were performed in 60 patients. The reoperation rate was $28.3 \%$ after a median duration of $8 \cdot 7$ years (range $2 \cdot 5-18$ years). $15 \%$ of patients who presented with mild stenosis subsequently required operation compared with $67 \%$ of those with moderate stenosis. There were no sudden unexpected deaths and no deaths after aortic valvotomy, except in those presenting with critical stenosis. Mortality was $16 \cdot 7 \%$ but patients presenting with critical aortic stenosis had a much worse prognosis. Actuarial and hazard analysis showed that the survival and absence of serious events (aortic valve surgery or balloon dilatation, endocarditis, or death) were significantly better in patients who presented with mild aortic stenosis than in those who presented with moderate aortic stenosis. $75 \%$ of patients presenting with mild stenosis had not progressed to moderate stenosis after 10 years of follow up.

Conclusions-Congenital aortic valve stenosis may be progressive even when it is mild at presentation. Patients presenting with mild stenosis, however, have a significantly better prognosis than those presenting with moderate stenosis. An accurate clinical and echocardiographic assessment of the severity of aortic valve stenosis at presentation provides a good guide to prognosis into early adult life.

(Br Heart f 1993;69:71-79)

Congenital aortic valve stenosis is known to be a progressive disease. ${ }^{13}$ However, the longterm prognosis of children presenting with mild or moderate stenosis is unclear. ${ }^{245}$ Earlier studies performed without cardiac catheterisation or Doppler echocardiography did not provide haemodynamic information. In addition, subaortic and rheumatic aortic stenosis were not clearly distinguished from congenital aortic valve stenosis. ${ }^{12}$ Mild aortic stenosis may not have been included in these studies because of the difficulty in accurate clinical diagnosis. $^{267}$ Most recent long-term studies have examined only the postoperative results. ${ }^{810}$

The aims of this study were to determine the incidence and severity of congenital aortic valve stenosis at presentation in a defined population and to assess its progression, to provide guidelines on prognosis into early adult life.

\section{Patients and methods}

Patient details were obtained from the Liverpool Congenital Malformations Registry and the Heart Clinic records of the Royal Liverpool Children's Hospital. The malformations register provided a record of children with congenital abnormalities born in the Liverpool area. From 1960 to 1978 it included children born in the Liverpool and Bootle districts only, but from 1979 it was extended to include the five Health Districts of Liverpool that make up the Merseyside area. Live birth rates and the total number of children with congenital heart disease born in the defined areas were available for these periods. The incidence of congenital heart disease recorded in the malformations register was $7 \cdot 4$ per 1000 live births, which because it is close to the expected incidence for the population indicates that the notification rate was high. The register has been used in other studies to determine the incidence of congenital heart disease in the Liverpool area. ${ }^{11} 12$

All patients with suspected congenital heart disease born in the Merseyside area are referred to the Heart Clinic which is the local 
Table 1 Criteria for the classification of the severity of aortic valve stenosis and the median age at presentation for each group

\begin{tabular}{|c|c|c|c|c|c|c|}
\hline & $\begin{array}{l}\text { Number of } \\
\text { patients } \\
(\%)\end{array}$ & $\begin{array}{l}\text { Clinical } \\
\text { criteria }\end{array}$ & $E C G$ & $\begin{array}{l}\text { Doppler } \\
\text { velocity } \\
(\mathrm{m} / \mathrm{s})\end{array}$ & $\begin{array}{l}\text { Catheter } \\
\text { gradient } \\
(\mathrm{mm} / \mathrm{Hg})\end{array}$ & $\begin{array}{l}\text { Median age } \\
\text { at presentation } \\
\text { (mnth) }\end{array}$ \\
\hline Bicuspid valve & $\begin{array}{l}39 \\
(16 \cdot 3)\end{array}$ & $\begin{array}{l}\text { EC } \\
\text { ESM }\end{array}$ & Normal & $<2.0$ & $<10$ & $\begin{array}{l}11 \cdot 5 \\
(0-181)\end{array}$ \\
\hline Mild stenosis & $\begin{array}{l}145 \\
(60 \cdot 7)\end{array}$ & $\begin{array}{l}\text { Short } \\
\text { ESM }\end{array}$ & Normal & $2-2 \cdot 9$ & $11-40$ & $\begin{array}{l}23 \cdot 5 \\
(0-178)\end{array}$ \\
\hline Moderate stenosis & $\begin{array}{l}33 \\
(13 \cdot 8)\end{array}$ & $\begin{array}{l}\text { Long } \\
\text { ESM }\end{array}$ & $\begin{array}{l}\text { Normal or } \\
\text { LVH }\end{array}$ & $3-4 \cdot 5$ & $41-80$ & $\begin{array}{l}29 \cdot 7 \\
(0-245)\end{array}$ \\
\hline Severe stenosis & $\begin{array}{l}1 \\
(0 \cdot 4)\end{array}$ & Symptoms & $\begin{array}{l}\text { Normal } \\
\text { or LVH }\end{array}$ & $>4.5$ & $>80$ & 11.8 \\
\hline Critical stenosis & $\begin{array}{l}21 \\
(8 \cdot 8)\end{array}$ & $\begin{array}{l}<3 \text { mnth } \\
\text { CCF }\end{array}$ & $\begin{array}{l}\text { or LV } \\
\text { strain }\end{array}$ & & & $\begin{array}{l}0 \cdot 25 \\
(0-2)\end{array}$ \\
\hline Total & 239 & & & & & 16 \\
\hline
\end{tabular}

supraregional cardiac unit. Patients who were not born in the Merseyside area were excluded from this study. In most cases the information was the same from both sources, but one child with critical aortic stenosis was identified from the malformations register, the diagnosis having been made at postmortem.

Between 1 January 1960 and 31 December 1989, 239 children (155 male, 84 female) with congenital aortic valve stenosis were born in the Merseyside area. Patients with a bicuspid aortic valve were included because this can become stenotic. ${ }^{13-15}$ The severity of stenosis at presentation was determined from the clinical findings and electrocardiogram in all patients. Results of Doppler echocardiography and cardiac catheterisation were included in the assessment if these investigations were performed within a year of presentation. The presence of aortic regurgitation and other cardiac lesions was noted.

There is no consensus on the classification of the severity of aortic stenosis in children. ${ }^{2-4}$ Table 1 shows the criteria used in this study, with the distribution of the different degrees of severity and median age at presentation in each group. In the group of patients with a bicuspid valve but no significant stenosis the diagnosis was confirmed on echocardiography at follow up. ${ }^{1618}$ Though four patients in the group with mild stenosis had electrocardiographic evidence of left ventricular hypertrophy, ${ }^{19}$ all had a peak aortic valve gradient at cardiac catheterisation of less than $40 \mathrm{~mm} \mathrm{Hg}$ or a velocity ${ }^{2022}$ of less than $3.0 \mathrm{~m} / \mathrm{s}$ measured by continuous wave Doppler. In the group of patients with moderate stenosis severity was assessed on clinical and electrocardiographic criteria in 10

Table 2 Distribution of 127 additional cardiac lesions in 79 patients, indicating the incidence in patients under or over 1 year of age

\begin{tabular}{llll}
\hline & $<1$ year & $>1$ year & $\begin{array}{l}\text { \% of } \\
\text { study group }\end{array}$ \\
\hline Coarctation & 44 & 9 & 22 \\
Patent ductus arteriosus & 41 & 2 & 18 \\
Atrial septal defect & 1 & 0 & $0 \cdot 4$ \\
Atrioventricular septal defect & 1 & 0 & $0 \cdot 4$ \\
Ventricular septal defect & 19 & 0 & 8 \\
Mitral valve abnormality & 7 & 0 & 3 \\
Right ventricular outflow obstruction & 3 & 0 & 1 \\
Total & 116 & 11 & \\
& $(91 \cdot 3 \%)$ & $(8 \cdot 7 \%)$ & \\
\hline
\end{tabular}

$44 \%$ of patients had more than one lesion. patients, was made at cardiac catheterisation in 16 patients, was based on continuous wave $\vec{\omega}$ Doppler echocardiography in three patients, and was performed at postmortem in the remaining four patients. The diagnosis was confirmed at operation or postmortem in all patients with severe or critical stenosis. Most patients (216) had isolated valve stenosis or a bicuspid aortic valve. In 21 patients there was additional subvalve stenosis and in two patients there was both subvalve and supravalve stenosis. Mild aortic regurgitation occurred in seven patients. No patient had moderate or $\vec{\oplus}$ severe regurgitation at presentation.

Additional cardiac lesions were significantly more frequent in patients presenting under the age of one year $(p<0.0001)$. Table 2 shows the distribution of these lesions. Other cardiac lesions were also significantly more common in patients presenting with severe or critical $\overrightarrow{\vec{O}}$ stenosis than in the rest of the group ( $p<3$ 0.001 ). They occurred in 15 of the 22 patients with severe or critical stenosis, compared with 13 of the 33 patients in the moderate group, and 51 of the 184 presenting with mild stenosis. Five patients had Turner's syndrome and one had Noonan's syndrome. Trisomy 15 occurred in one patient and trisomy $13 \%$ (Patau's syndrome) in another, the diagnosis being confirmed by chromosomal studies.

\section{FOLLOW UP}

The case notes of all patients were reviewed and details of all events such as cardiac catheterisations, balloon dilatations, endocarditis, cardiac surgery, and death were recorded. An attempt was made to contact all patients and only seven patients were lost to follow up. Clinical examination, 12 lead electrocardiogram, and cross sectional and continuous wave Doppler $(1.9$ or $2.0 \mathrm{MHz})$ echocardiography were performed in $170 \stackrel{\mathbb{Q}}{\Omega}$ patients by DK. Echocardiography was per- $\mathbb{\otimes}$ formed with an Irex Meridian or HewlettPackard Sonos 500 ultrasound system. In the remaining 22 patients data were obtained from 0 the adult cardiologist maintaining follow up. The aim was to determine the current severity of aortic stenosis and regurgitation.

STATISTICAL ANALYSIS

Descriptive statistics are presented as median with range for continuously distributed vari- 
Table 3 Number and type of operations and the median aortic valve gradient at operation and number of operations for aortic regurgitation

\begin{tabular}{lllllll}
\hline & $\begin{array}{l}\text { Number of } \\
\text { operations }\end{array}$ & Valvotomy (\%) & $\begin{array}{l}\text { Valvotomy }+ \\
\text { LVT surgery }\end{array}$ & $\begin{array}{l}\text { Aortic valve } \\
\text { replacement } \\
(\%)\end{array}$ & $\begin{array}{l}\text { Median } \\
\text { gradient at } \\
\text { operation } \\
(\mathrm{mm} / \mathrm{Hg})\end{array}$ & $\begin{array}{l}\text { Operations for } \\
\text { aortic } \\
\text { regurgitation }\end{array}$ \\
\hline 1st operation & 60 & $44(73)$ & $13(22)$ & $3(5)$ & $65(50-140)$ & 1 \\
2nd operation & 17 & $6(35)$ & 0 & $11(65)$ & $70(20-120)$ & 5 \\
3rd operation & 4 & 0 & 0 & $4(100)$ & $20(20-110)$ & 3 \\
Total & 81 & 50 & 13 & 18 & & 9 \\
\hline
\end{tabular}

LVOT, left ventricular outflow tract.

ables or as proportions with $70 \%$ confidence intervals (CI) for categorical variables. The possibility that differences were related to something other than chance was explored by the Wilcoxon rank sum test or the $\chi^{2}$ statistic $^{24}$ as appropriate. Freedom from disease progression, death, first significant event after presentation (aortic valve surgery or balloon dilatation, endocarditis, or death) and reoperation in those receiving surgical intervention for aortic valve disease, was analysed actuarially by the product-limit method of Kaplan and Meier. ${ }^{25}$ Resultant distributions for death and first event were modelled parametrically and the hazard function determined. ${ }^{26}$ Incremental risk factors for these events were elucidated by multivariate analyses performed in the hazard function domain. ${ }^{26}$ Variables were regarded as significant when their probability value was equal to or less than 0.2 . In addition, the increment in information relating to the event of interest contributed by each significant factor was evaluated in the log likelihood domain. ${ }^{27}$ The variables considered in the multivariate analyses were the severity of aortic stenosis at presentation (and transforms), age at presentation (and transforms), sex, presence of syndromes, associated cardiac lesions, and aortic regurgitation at presentation.

\section{Results}

Congenital aortic valve stenosis occurred in 90 of the 239, 669 live births in the Liverpool and Bootle areas from 1960 to 1978 , giving an

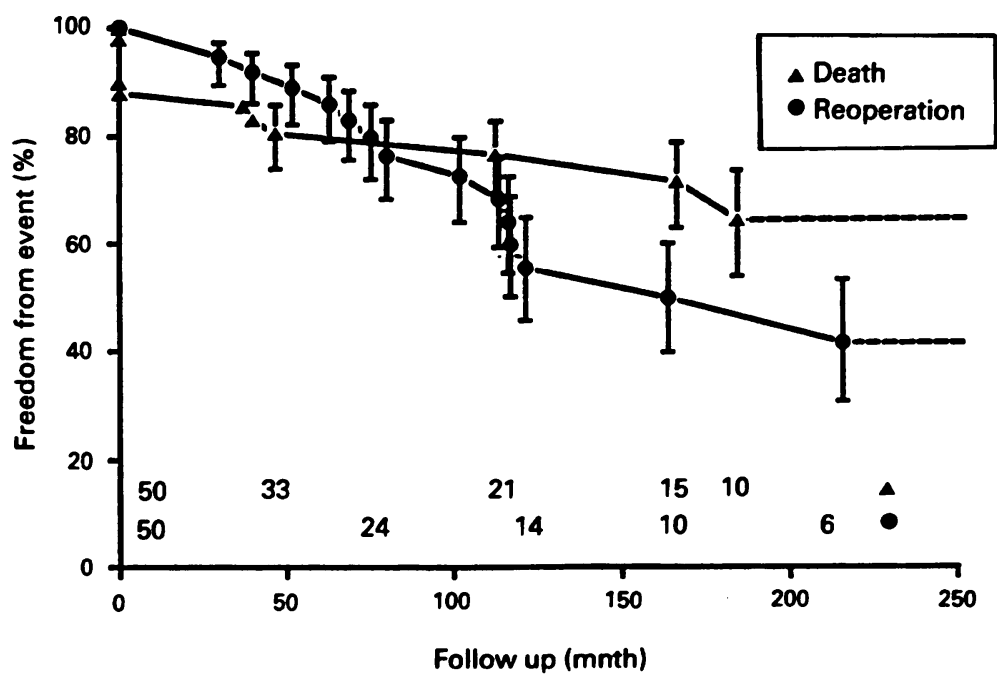

Figure 1 Actuarial freedom from death and reoperation rates in 50 patients who presented with insignificant, mild, or moderate aortic stenosis combined and later required operation. Broken lines beyond the last event show the continued follow up of patients free of the events of interest. Bars are $70 \%$ confidence intervals. incidence of 3.8 per 10,000 live births. Between 1979 and 1989 congenital aortic valve stenosis occurred in 105 of the 224, 558 live births in the five health districts of the Merseyside area, giving an incidence of 4.7 per 10000 live births. This represents $5 \cdot 7 \%$ of cases of congenital heart disease in the Merseyside area during this period. The remaining 44 patients were born between 1960 and 1978 within the Merseyside area but outside the Liverpool and Bootle area and therefore they are not included in the calculated incidence.

FOLLOW UP

The 239 patients were followed for 2261 patient-years. The median duration of follow up in survivors was 9.2 years (range $0.48-28 \cdot 1$ years), with $68 \%, 16 \%$ and $5 \%$ being followed to 5,15 and 25 years respectively. Seven patients with mild aortic stenosis at presentation who showed no increase in severity over a period of 1-15 years (median 6 years), were lost to further follow up at the date of study closure.

SURGERY

Sixty patients $(25 \%)$ underwent 81 operations for aortic stenosis (table 3). The indications for operation were a peak aortic valve gradient at cardiac catheterisation of $>60 \mathrm{~mm} \mathrm{Hg}$, the development of symptoms, or the presence of left ventricular strain pattern on the electrocardiogram. $^{23}$ Surgery was performed significantly more frequently in patients who presented with moderate stenosis than in those with mild stenosis $(p<0.0001)$. Twenty two of the 33 patients who presented with moderate stenosis progressed to require operation compared with 28 of the 184 patients who presented with mild stenosis. Ten patients (46\%) with severe or critical stenosis at presentation underwent operation and the remaining 12 died before the operation could be performed. There was no significant difference in the median age at first operation between those presenting with mild stenosis $(10.5$ years; range $4 \cdot 8-22 \cdot 4)$ and those presenting with moderate stenosis $(6.9$ years; range $0 \cdot 28-16.9)$. The median age at operation in those presenting with critical stenosis was 1.6 weeks (range $0 \cdot 3-25.5$ weeks). One operation was performed in 43 patients $(72 \%), 13$ patients $(22 \%)$ had two operations, and four patients $(7 \%)$ had three operations. The reoperation rate was $28 \%$.

We examined the outcome in patients who underwent operation. Those with critical aortic stenosis were considered separately because they are known to have a very different 
prognosis. ${ }^{28}$ Figure 1 shows the actuarial analysis of freedom from reoperation or death in the 50 patients who presented with mild or moderate stenosis and subsequently underwent operation. There was a relatively constant requirement for reoperation between three and 10 years after the initial operation. Beyond this time, the requirement fell: however, this inference is based on only 14 patients. The proportions of patients free from reoperation at five and 10 years were $89 \%$ and $60 \%$ respectively. Survival rates were $81 \%$ and $77 \%$ at five and 10 years respectively. The median duration between the first and second operations was 8.7 years (range 2.5-18 years). Continuous wave Doppler velocities were recorded at follow up in the 38 surviving patients. In 14 patients the velocity was less than $3 \mathrm{~m} / \mathrm{s}$, in 20 patients it was between 3 and $3.9 \mathrm{~m} / \mathrm{s}$, and in four patients it was $4 \mathrm{~m} / \mathrm{s}$ or greater. Seven of the 10 patients with critical aortic stenosis who underwent surgery died (six within a month of surgery and one after 4 months from cardiac failure). Of the three remaining patients, one has mild, one moderate, and one severe stenosis judged by Doppler echocardiography.

BALLOON DILATATION

Balloon dilatation of the aortic valve was performed in seven patients. In three patients this followed aortic valvotomy and in four patients it was the primary treatment.

BACTERIAL ENDOCARDITIS

Endocarditis of the aortic valve occurred in three patients $(1.3$ per 1000 patient-years of follow up).

AORTIC REGURGITATION

Aortic regurgitation was found in $55(28.6 \%)$ of the 192 surviving patients who have been

Table 4 Cause of death in the 21 patients who did not undergo surgery and the severity of stenosis at presentation

\begin{tabular}{llll}
\hline & Aortic stenosis & $\begin{array}{l}\text { AS and other } \\
\text { cardiac lesion }\end{array}$ & Other cardiac lesion \\
\hline Bicuspid valve & 0 & 0 & $1^{\star}+$ \\
Mild stenosis & 0 & 0 & $3^{\star} \dagger$ \\
Moderate stenosis & 0 & $5^{\star} \ddagger$ & 0 \\
Severe stenosis & 1 & $0^{\star}$ & 0 \\
Critical stenosis & 9 & $2^{\star}$ & 4 \\
Total & 10 & 6 & \\
\hline
\end{tabular}

${ }^{\star}$ Coarctation and patent ductus arteriosus; tventricular septal defect; $\ddagger$ trisomy 15 ( 1 patient). AS, aortic stenosis.

Table 5 Cause of death in the 19 patients who died after operation and severity of stenosis at presentation

\begin{tabular}{|c|c|c|c|c|}
\hline \multirow[b]{2}{*}{$\begin{array}{l}\text { Severity } \\
\text { at } \\
\text { presentation }\end{array}$} & \multicolumn{3}{|c|}{ Early postoperative deaths } & \multirow{2}{*}{$\begin{array}{l}\text { Late } \\
\text { post- } \\
\text { operative } \\
\text { deaths }\end{array}$} \\
\hline & Valvotomy & $\begin{array}{l}\text { Aortic } \\
\text { valve } \\
\text { replacement }\end{array}$ & $\begin{array}{l}\text { Other } \\
\text { cardiac } \\
\text { lesions }\end{array}$ & \\
\hline Mild stenosis & & 3 & & $1^{\star}$ \\
\hline Moderate stenosis & $1 t$ & 4 & $3 \ddagger$ & \\
\hline $\begin{array}{l}\text { Severe stenosis } \\
\text { Critical stenosis }\end{array}$ & 6 & & & 1 \\
\hline Total & 7 & 7 & 3 & 2 \\
\hline
\end{tabular}

*Severe kyphoscoliosis; fundiagnosed subaortic stenosis; łmalalignment ventricular septal defect, coarctation/interrupted aortic arch, and patent ductus arteriousus.

Early postoperative deaths were deaths $<30$ days after operation. followed up. It occurred spontaneously in 24 patients, as a result of aortic valvotomy in 27 patients, and in association with aortic valve replacement in two patients. In one patient it followed balloon dilatation in one and bacterial endocarditis in another. It was mild in 44 patients $(22.9 \%)$ and moderate in 11 patients $(5 \cdot 7 \%)$. Nine operations were performed in seven patients for severe aortic regurgitation. In one patient this was the first operation and followed bacterial endocarditis on a stenotic aortic valve. In the other six patients aortic regurgitation requiring reoperation followed aortic valvotomy on five occasions and aortic valve replacement on three occasions.

SURVIVAL

There were 40 deaths $(16 \cdot 7 \%)$. Table 4 shows the causes of death in those who did not undergo operation. There were no sudden unexpected deaths. All deaths occurred before operation could be performed or in association with other cardiac lesions in patients with severe or critical stenosis. There were no deaths after simple valvotomy other than in patients presenting with critical aortic stenosis. In one case there was undiagnosed subaortic stenosis, and the other deaths were associated with aortic valve replacement or the presence of other important cardiac lesions. The one late death was in a child with severe kyphoscoliosis in whom reoperation was thought to carry a high risk.

Severe and critical aortic stenosis had a high mortality (19 patients $86 \%$ ); in seven death followed surgical intervention. However, examination of actuarial cumulative hazard plots stratified by severity of aortic stenosis at presentation confirmed a high degree of parallelism between these groups (Blackstone $\mathrm{EH}$, 1991; personal communication). The validity of developing the parametric equation on the total data set $(n=239)$ was confirmed by including the severity of aortic stenosis at presentation as the only risk factor and comparing predicted survival rates with those observed from the stratified actuarial analyses (Blackstone EH, 1991, personal communication).

Figure 2 shows the actuarial survival from the date of presentation of the study group and that of normal population with a similar age/ sex distribution. ${ }^{29}$ To determine the prognosis from presentation we did not use selection or censoring when the natural history was modified in those patients who progressed and required surgical intervention. Patients with a bicuspid aortic valve were included in the mild group because $16(41 \%)$ were found to have mild stenosis at follow up. Analysis demonstrated a significant difference in survival between these groups. Survival in those patients who presented with mild disease was lower than the matched control population from 1 week because of the two early deaths that were associated with other cardiac lesions. Five and 20 year survival in this group was $97 \cdot 8 \%$ and $93.9 \%$. This was significantly better than the $72 \cdot 2 \%$ and $45.6 \%$ for the moderate group. The prognosis of patients who pre- 


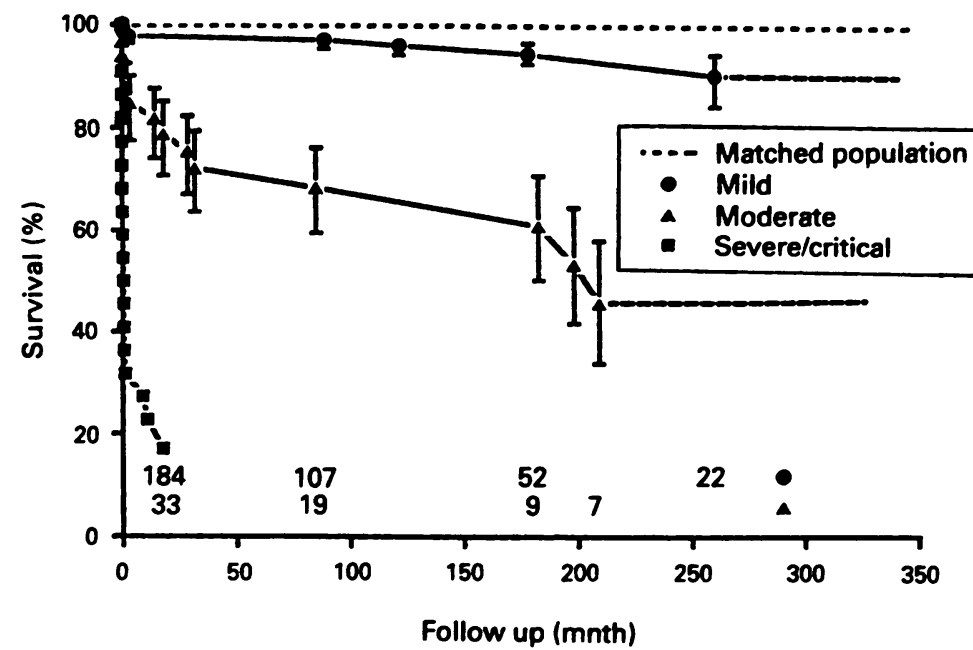

Figure 2 Actuarial survival rates from the time of presentation in patients presenting with insignificant/mild, moderate, and severe/critical aortic stenosis. Upper broken line shows the documented ${ }^{39}$ survival rates in a population matched to the age and sex distributions of the study group. Broken lines beyond the last event show the continued follow up of live patients. By convention the last event for the severe/critical group has not been plotted. Bars are $70 \%$ confidence intervals.

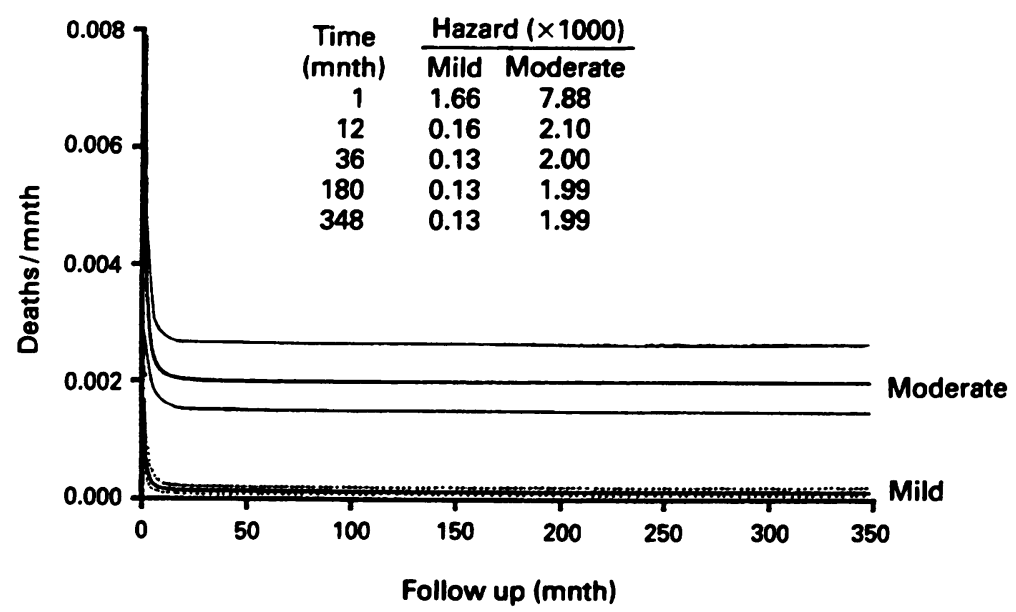

Figure 3 Variation in the monthly risk of death plotted from the solutions to equations developed in the hazard function domain (Appendix I) for the syndrome-free patient presenting at two years of age with either mild or moderate aortic stenosis. Broken lines show $70 \%$ confidence interval.

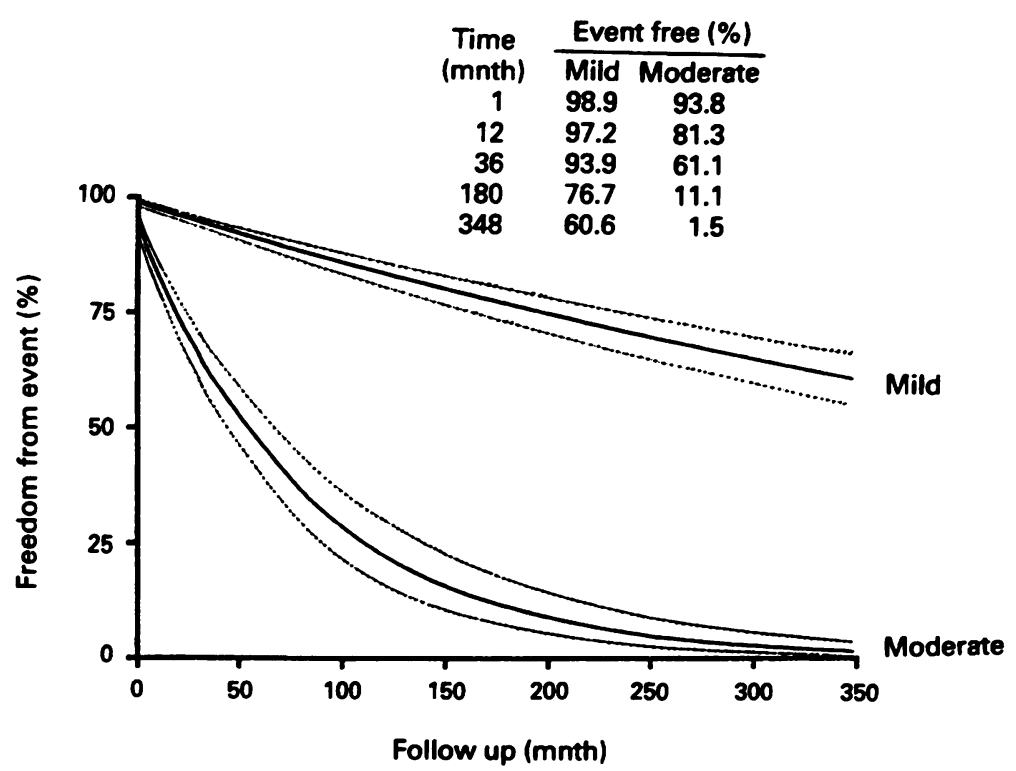

Figure 4 Predicted freedom from first significant event (aortic valve surgery or balloon dilatation, endocarditis, or death) plotted from equations developed in the hazard function domain (Appendix I) for a male patient without other cardiac lesions presented at two years of age with either mild or moderate aortic stenosis. Broken lines show the $70 \%$ confidence interval. sented with severe and critical stenosis was poor with only three of the 22 patients alive, and the longest period of follow up was less than 3 years. Multivariate analysis was carried out to assess the risk factors for death. It showed two phases of hazard for death-an early rapidly declining phase and a constant phase. The magnitude of the early phase was increased with severity of aortic stenosis at presentation ( $p \leqslant 0.0001)$ and younger age at presentation ( $p=0.0003$, natural logarithm transform) (Appendix I). The constant phase hazard was increased by increased severity of aortic stenosis at presentation ( $p \leqslant 0.0001$ ) and the presence of a syndrome $(p=0.0205)$. In terms of information contribution, the severity of aortic stenosis at presentation from both phases accounted for $59.7 \%$ when assessed in the log likelihood domain. Young age contributed $37.9 \%$ and syndromes the remaining $2 \cdot 4 \%$ (Appendix I).

Figure 3 shows the predicted risk of premature death for a patient without a syndrome who presented at 2 years of age. Therefore the only variable remaining free is the severity of aortic stenosis at presentation, allowing the true effect of this factor to be examined. Figure 3 shows that the risk of premature death is significantly greater in the child presenting with moderate stenosis than with mild stenosis. The table within the figure indicates that the risk of death is $\mathbf{1 5}$ fold greater in the child presenting with moderate stenosis compared with mild stenosis from the second year after presentation.

EVENT-FREE SURVIVAL

Multivariate analysis was also used to assess the risk of a significant event developing (aortic valve surgery or balloon dilatation, endocarditis, or death). As with freedom from death, there were two phases of hazard for any significant event. There was an early rapidly declining phase followed by a constant phase. The early phase was slightly more acute and the hazard rate consistently greater. Risk factors (Appendix I) for the early phase were more severe aortic stenosis at presentation ( $p$ $\leqslant 0.0001$, square transform), younger age ( $p$ $\leqslant 0.0001$,negative reciprocal transform), and being male $(p=0.073)$. The constant phase was associated with more severe aortic stenosis at presentation ( $p \leqslant 0.0001$ ) (Appendix I) and presence of associated cardiac anomalies $(p=$ 0.008 ). Information contributed by the severity of aortic stenosis at presentation was $89 \%$ when combined from both phases (Appendix I).

Figure 4 predicts the chance of being free from a significant event for a male patient presenting at two years of age with isolated mild or moderate aortic stenosis. The only variable is therefore the difference in the severity of aortic stenosis at presentation. It shows that the risk of a significant event is much higher in a patient who presents with moderate stenosis compared with mild stenosis. After 20 years of follow up the chance of being free of a significant event is $69.4 \%$ for the child presenting with mild stenosis and only 


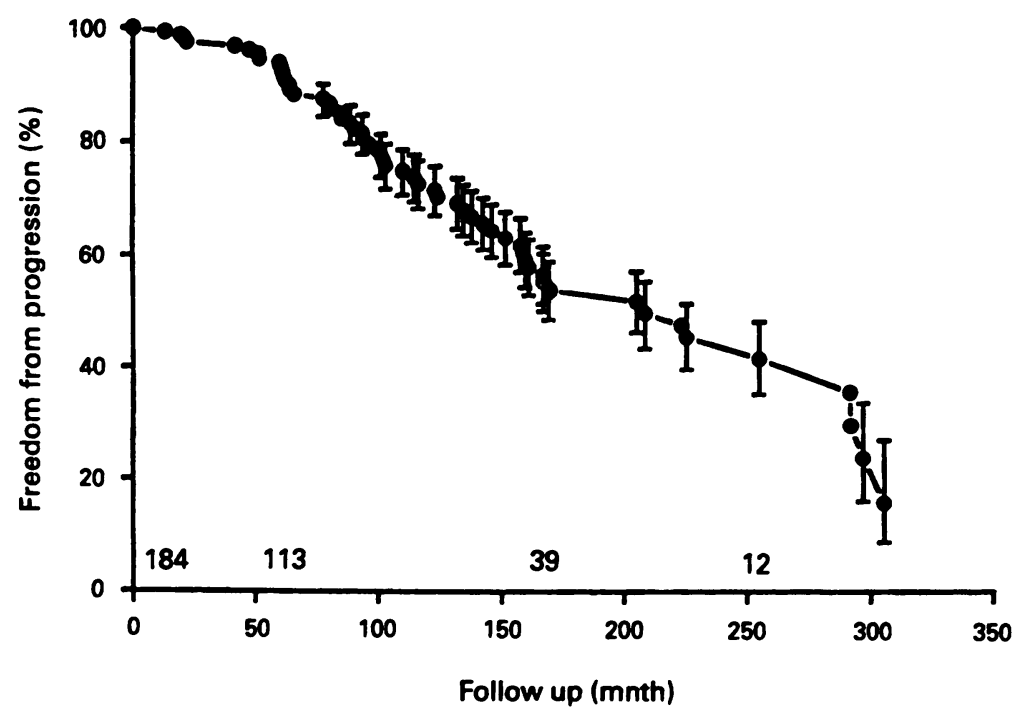

Figure 5 Actuarial analysis of progression from the time of presentation in the 184 patients who presented with mild or insignificant aortic stenosis. By convention the last event has not been plotted. It occurred 319 months after presentation. Bars are $70 \%$ confidence intervals. $a .^{7}$ Because echocardiography was not available the assessment of severity was essentially based on clinical criteria and several children with mild stenosis were excluded.

A peak aortic valve gradient of less than 50 $\mathrm{mm} \mathrm{Hg}$ has been viewed as an indication of $\underline{\underline{w}}$ mild stenosis in some studies. ${ }^{23}$ However, this $I$ is the gradient at which aortic valvotomy is $\stackrel{\mathbb{D}}{\stackrel{1}{2}}$ considered in children ${ }^{893}$ and Hossack et al $\stackrel{7}{\mathrm{C}}$ stated that "all patients with a pressure differ- $\stackrel{.}{\Rightarrow}$ ence greater than $40 \mathrm{~mm} \mathrm{Hg}$ were judged moderate or severe on physical signs".

Therefore, a cardiac catheterisation gradient $\frac{\bar{\sigma}}{\overline{\mathrm{T}}}$ of more than $40 \mathrm{~mm} \mathrm{Hg}$ or a Doppler velocity of more than $3 \mathrm{~m} / \mathrm{s}$ was taken as evidence of $\stackrel{\varnothing}{\circ}$ moderate stenosis for our study. The cardiac is catheterisation instantaneous gradient and $\overrightarrow{0}$ maximal Doppler velocity correspond closely ${ }^{22}$ and studies have confirmed the value of Dop- $\omega$ pler echocardiography in the determination of the severity of aortic stenosis. ${ }^{34-36}$ An accurate assessment of severity can currently be made by correlating the clinical, electrocardiographic, and echocardiographic findings in any patient.

$4.7 \%$ in a similar patient presenting with moderate stenosis.

CURRENT STATUS

Almost all patients who presented with moderate, severe, or critical stenosis underwent some form of intervention or died during the follow up. Patients who presented with insignificant or mild stenosis seemed to have a much better prognosis. However, 58 of these patients progressed to moderate stenosis (as defined by a Doppler velocity of $>3 \mathrm{~m} / \mathrm{s}$ at follow up) or underwent aortic valve surgery or balloon dilatation during follow up. Of the 39 patients who presented with a bicuspid aortic valve without stenosis, none progressed to moderate stenosis or required intervention. Figure 5 shows the actuarial analysis of progression to moderate or severe stenosis in the 184 patients who presented with mild or insignificant stenosis. It shows that stenosis in all patients followed up to 23 years had progressed. However, the number of those followed for more than 15 years is relatively small, making predictions after this time less reliable. The median duration of follow up was greater in those in whom stenosis did progress, and such progression was more likely in those who presented early. These differences were not statistically significant, however.

\section{Discussion}

The prognosis of critical aortic stenosis is well documented, ${ }^{30}$ but that in the milder degrees of stenosis is unclear. Criteria for admission of patients with aortic stenosis into the Joint Study on the Natural History of Congenital Heart Defects, ${ }^{2}$ included cardiac catheterisation on at least two occasions. Mild aortic stenosis was therefore excluded. In addition, no distinction was made between valve and subvalve stenosis. Recent studies relate mainly to the results of surgery ${ }^{810}$ in moderate and severe aortic stenosis. The only large study that examined the prognosis of children with mild stenosis is that of Hossack et
EPIDEMIOLOGY

The incidence of aortic valve stenosis in patients with congenital heart disease born in the Merseyside area is similar to the $3-6 \%$ of $\overrightarrow{0}$ cited in other series. ${ }^{37}{ }^{39}$ The incidence in this study may be a little lower than the true incidence for several reasons. Patients who moved from the area before diagnosis will not have been included. Infants who died from critical stenosis are likely to have been included $\stackrel{\mathbb{Q}}{\circ}$ because of referral of information to the $\overline{\bar{o}}$ Malformations Registry, ${ }^{112}$ but sudden death in an older patient may have been missed. However, sudden death has not been reported in patients without severe stenosis ${ }^{7}$ and it is $\vec{\otimes}$ unlikely that a patient with the significant murmur of severe aortic stenosis would not have been referred to the local Heart Clinic. Even if there were undiagnosed cases in patients who died suddenly, the number would be small as most patients have mild stenosis at $\stackrel{\circ}{5}$ presentation. $^{7}$ The incidence for the period $\frac{7}{0}$ 1960-1978 was less than in the subsequent years, possibly for the reasons given above. The $\stackrel{\sim}{\circ}$ incidence of bicuspid aortic valve is lower than $N$ the $1 \%$ of the population described by N Roberts ${ }^{40}$ from his postmorten series. This 0 may be because no murmur was detected or, when present, was thought to be innocent. Cross sectional and Doppler echocardiography have made the diagnosis of a bicuspid aortic $\underline{T}$ valve easier. ${ }^{14-16}$ Screening of large numbers of $\frac{}{D}$ children by echocardiography is the only way

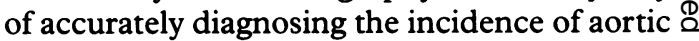
stenosis, and until this is done the true incidence will not be known.

Most patients presented with mild stenosis. As this study includes almost all children born with congenital aortic valve stenosis in the area, it indicates the distribution of the severity of stenosis in the population. The age and sex distribution is similar to other studies ${ }^{279}$ with males more commonly affected. Patients with critical stenosis presented with circulatory 
failure in the first few months of life, but in the other groups the median age at presentation was about two years. The wide age range reflects the fact that some children presented early, usually with additional cardiac lesions, while in others a murmur was heard later in life.

Although congenital aortic valve stenosis is not usually associated with other abnormalities of the left ventricular outflow tract, additional subvalve and supravalve stenosis can occur, ${ }^{41-43}$ as it did in $9.6 \%$ of this series. The additional cardiac lesions found in this series were similar to other studies, ${ }^{314344}$ occurring more commonly in patients presenting with critical aortic stenosis and in those under a year of age. Because critical stenosis occurs in this younger age group, it is difficult to separate its effect and that of age. Turner's syndrome is known to be associated with aortic valve stenosis, ${ }^{45} 46$ but trisomy 13 and 15 are rare conditions not normally associated with aortic stenosis.

Most patients were traced and re-examined and the median duration of follow up of $9 \cdot 2$ years in survivors makes our predictions of the prognosis into early adult life reliable.

\section{OPERATION}

Surgery was required by significantly fewer patients who presented with mild than with moderate stenosis, indicating that many patients in this group stenosis remains mild over a long period. Most patients who presented with moderate stenosis required operation within the follow up period.

In the assessment of the long term prognosis of patients who have undergone operation, infants presenting with critical aortic stenosis were studied separately to compare this series with other long term studies that only included patients presenting over a year of age. ${ }^{810}$ Actuarial analysis of the postoperative result in patients who presented with mild or moderate stenosis and who progressed to require operation (fig 1) showed that $60 \%$ had not required reoperation and the actuarial survival was $77 \%$ after 10 years of follow up. The median duration between first and second operations was 8.7 years and this is similar to some series, ${ }^{47}$ but shorter than others in which the median interval between first and second operation was $17 \cdot 7$ years. ${ }^{10}$ Valvotomy was performed on children with moderate stenosis (median gradient $65 \mathrm{~mm} \mathrm{Hg}$ ) to minimise the risk of sudden death, which occurs in approximately $1 \%$ of patients. ${ }^{43}$ The validity of this approach was substantiated by the fact that there were no sudden deaths, and no deaths after simple valvotomy, which is recognised as effective and relatively safe palliation. ${ }^{10}$ However, this must be balanced against the fact that $30-40 \%$ of these patients will require reoperation $^{91047}$ within 10 to 20 years, and that approximately $70 \%$ of these reoperations will be aortic valve replacements, ${ }^{11047}$ as was found in this study. In the 38 patients who survived operation, $90 \%$ had an acceptable postoperative Doppler velocity of less than 4 $\mathrm{m} / \mathrm{s}$. However, six patients had moderate aortic regurgitation which may affect prognosis. ${ }^{10}$

The low rate of operation in children with critical aortic stenosis reflects the fact that some presented in the early years of the study and died before operation could be attempted.

BALLOON DILATATION

Balloon Dilatation was performed in a few patients during the study period. This has now become a much more commonly used procedure at this unit because it provides adequate palliation for both initial and recurrent stenosis. ${ }^{49} 50$

The incidence of bacterial endocarditis was similar to other series. ${ }^{48}$ Aortic regurgitation became more significant at follow up, increasing from $3 \%$ to $29 \%$, with a further $3.6 \%$ of patients requiring operation for severe regurgitation.

SURVIVAL

Patients presenting with mild stenosis have a significantly better prognosis than patients presenting with moderate stenosis. The survival rates for patients who presented with mild disease resembles that in the general population. Long-term survival in our group with moderate stenosis accords with other series. ${ }^{18}$ Those with severe and critical stenosis had a poor outcome with a high early mortality.

When we examined the cause of death in the group that died without surgery (table 4 ) we found no sudden, unexpected deaths. Twelve patients with severe or critical stenosis died before operation could be performed. All the other deaths were associated with additional cardiac lesions that were thought to be an important contributory cause of death. However, the presence of these other cardiac lesions did not emerge as a significant independent risk factor for death because death was more strongly associated with younger age at presentation. The small contribution from the presence of a syndrome was attributable to the two deaths that occurred, independently of other risk factors, at six months and 23 years in the patients with trisomy 13 and 15 .

Figure 3 emphasises the significantly lower risk of death in patients who present with mild rather than moderate stenosis, in whom other risk factors essentially have been neutralised. The risk of death was approximately 15 times greater in those presenting with moderate stenosis after the initial year after presentation. The hazard rate for death for a patient with mild diseases runs very close to the $\mathrm{x}$ axis. This emphasises the favourable prognosis in this group.

EVENT-FREE SURVIVAL

Multivariate analysis (fig 4) also showed that the patient who presented with mild stenosis had a much lower risk of developing important complications in the long term than the patient who presented with moderate stenosis.

CURRENT STATUS

The evaluation of the current status of patients who presented with mild or insignificant sten- 
osis emphasises that most patients who presented with mild stenosis had a good prognosis. Mild stenosis, however, does seem to progress with time.

This study shows the range of congenital aortic valve stenosis in the Merseyside area over a 30 year period and shows that $60 \%$ of patients had mild stenosis at presentation. It indicates that aortic stenosis is progressive, but that the outcome in children presenting with mild aortic stenosis was considerably better than those presenting with moderate disease. Prognosis into early adult life can be predicted by an accurate clinical and echocardiographic assessment of the severity of aortic stenosis at presentation.

1 Campbell $\mathrm{M}$. The natural history of congenital aortic stenosis. Br Heart $\mathcal{F} 1968 ; 30: 514-26$.

2 Wagner HR, Ellison RC, Keane JF, Humphries JO, Nadas AS. Clinical course in aortic stenosis. Circulation 1977;56(suppl I):47-56.

3 Mody MR, Mody GT. Serial haemodynamic observations in congenital valvular and subvalvular aortic stenosis. $\mathrm{Am}$ Heart $f 1975 ; 89: 137-43$.

4 Cohen LS, Friedman WF, Braunwald E. Natural history of mild congenital aortic stenosis elucidated by serial haemild congenital aortic stenosis elucidated by se
modynamic studies. Am $₹$ Cardiol 1972;30:1-5.

5 Kennedy KD, Nishimura RA, Holmes DR, Bailey KR Natural history of moderate aortic stenosis. $\mathcal{f} \mathrm{Am} \mathrm{Coll}$ Cardiol 1991;17:313-9.

6 Braunwald E, Goldblatt A, Aygen MM, Rockoff SD, Morrow AG. Congenital aortic stenosis. Clinical and haemodynamic findings in 100 patients. Circulation 1963;27:426-50.

7 Hossack KF, Neutze JM, Lowe JB, Barratt-Boyes BG. Congenital valvar aortic stenosis. Natural history and assessment for operation. Br Heart $\mathcal{F}$ 1980;43:561-73.

8 Jones M, Barnhart GR, Morrow AG. Late results after operations for left ventricular outflow tract obstruction. Am $\mathcal{f}$ Cardiol 1982;50:569-79.

9 Hsieh KS, Keane JF, Nadas AS, Bernhard WF, Castaneda AR. Long-term follow up of valvotomy before 1968 for
congenital aortic stenosis. Am 7 Cardiol 1986;58: congenital.

10 DeBoer DA. Robbins RC, Maron BJ, McIntosh CL, Clark RE. Late results of aortic valvotomy for congenital valvar aortic stenosis. An Thorac Surg 1990;50:69-73.

11 Kenna AP, Smithells RW, Fielding DW. Congenital heart disease in Liverpool: $1960-1969$. $Q \mathcal{F}$ Med 1975;44: $17-44$.

12 Dickenson DF, Arnold R, Wilkinson JL. Ventricular septal defect in children born in Liverpool 1960 to 1969 . Evaluation of natural course and surgical implications in an unselected population. Br Heart 7 1981;46:47-54.

13 Edwards JE. The congenitally bicuspid aortic valve. Circulation 1961;23:485-8.

14 Mills P, Leech G, Davies M, Leatham A. The natural history of a non-stenotic bicuspid aortic valve. Br Heart $\mathcal{f}$ 1978;40:951-7.

15 Roberts WC. The structure of the aortic valve in clinically isolated aortic stenosis. An autopsy study of 162 patients over 15 years of age. Circulation 1970;42:91-7.

16 Radford DJ, Bloom KR, Izukawa T, Moes CAF, Rowe RD. Echocardiographic assessment of bicuspid aortic valves. Angiographic and pathological correlates. Circulation 1976;53:80-5.

17 Emanuel R, Withers R, O'Brien K, Ross P, Feizi $O$. Congenitally bicuspid aortic valves. Clinicogenetic study of 41 families. $B r$ Heart $₹$ 1978;40:1402-7.

18 Leech G, Mills P, Leatham A. The diagnosis of a nonstenotic bicuspid aortic valve. Br Heart $f$ 1978;40: stenotic

19 Davignon A, Rautahariu P, Boisselle E, Soumis F, Megeles $M$, Choquette A. Normal ECG standards of infants and children. Paediatr Cardiol 1979/80;1:123-52

20 Hegrenaes L, Hatle L, Aortic stenosis in adults. Noninvasive estimation of pressure differences by continuous wave Doppler echocardiography. Br Heart f 1985;54: 396-404.

21 Yeager M, Yock PG, Popp R. Comparison of Dopplerderived pressure gradient to that determined at cardiac catheterisation in adults with aortic stenosis: implications for management. Am $¥$ Cardiol 1986;57:644-8.

22 Currie PJ, Hagler DJ, Seward JB, Reeder GS, Fyfe DA, Bove AA, Tajik AJ. Instantaneous pressure gradient: a Bove AA, Tajik AJ. Instantaneous pressure gradient: a
simultaneous Doppler and dual catheter correlative study. simultaneous Doppler and dual cath Cardiol 1986;7:800-6.
23 Hugenholtz PG, Lees MH, Nadas AS. The scalar electrocardiogram, vectorcardiogram and exercise electrocardiogram in the assessment of congenital aortic stenosis. gram in the assessment of
Circulation 1962;26:79-90.

24 Armitage P, Berry G. Statistical methods in medica research. 2nd ed. Oxford:Blackwell Scientific Publications, 1987:371-421.

25 Kaplan EL, Meier P. Nonparametric estimation from incomplete observations. Am Stat Ass f 1958;53. 457-81.

26 Blackstone EH, Naftel DC, Turner (Junior) ME. The decomposition of time varying hazard into phases, each incorporating a separate stream of concomitant information. $\mathcal{F}$ Am Stat Ass 1986;81:615-24.

27 Fisher RA. Statistical methods and scientific reference. 3rd ed. New York: Hafner Press. 1973:71-8.

28 Lakier JB, Lewis AB, Heyman MA, Stanger P, Hoffman JIE, Rudolph AM. Isolated aortic stenosis in the neonate. Natural history and haemodynamic considerations. Cir culation 1974;50:801-8.

29 Office of Population Censuses and Surveys. Mortality statistics - general; England and Wales. Government Statistical Services, 1988;Series DH,1, No 21:38.

30 Balaji S, Keeton BR, Sutherland GR, Shore DF, Monro JL Aortic valvotomy for critical aortic stenosis in neonates and infants aged less than one year. Br Heart $f 1989$; 61:358-60.

31 Karl TR, Sano S, Brawn WJ, Mee RBB. Critical aortic stenosis in the first month of life: surgical results in 26 infants. Ann Thorac Surg 1990;50:105-9.

32 Turley $\mathrm{K}$, Bove EL, Amato JJ, Iannettoni $\mathrm{M}$, Yeh Cotroneo JV, Galdieri RJ. Neonatal aortic stenosis. Thorac Cardiovasc Surg 1990;99:679-84.

33 Ankeney JL, Tzeng TS, Liebman J. Surgical therapy fo congenital aortic valvular stenosis. A 23 year experience. f Thorac Cardiovasc Surg 1983;85:41-8.

34 Odemuyiwa O, Bourke JP, Peart I, Been M, Heads A, Hall RJC. Valvar stenosis: a comparison of the clinical assessment, echocardiography, Doppler ultrasound and catheterisation. Int $\mathcal{F}$ Cardiol 1990;26:59-66.

35 Shub C, Jamil Tajik, Holmes Jr. D, Reeder GS, Freeman WK, Ilstrup DM, Smith HC. Doppler echocardiograph in aortic stenosis: feasibility and clinical impact. Int Cardiol 1990;28:57-66.

36 Galan A, Zoghbi WA, Quinones MA. Determination of severity of valvular aortic stenosis by Doppler echocardiography and relation of findings to clinical outcom and agreement with haemodynamic measurements determined at cardiac catheterisation. Am f Cardiol 1991 67:1007-12.

37 Hoffman JIE. The natural history of congenital isolated pulmonic and aortic stenosis. Ann Rev Med 1969; 20:15-28.

38 Keith JD, Rowe RD, Vlad P. Heart disease in infancy and childhood, ed 2. New York:McMillan 1967:3.

39 Nadas AS, Fyler DC. Paediatric cardiology, ed 3. Philadelphia:W.B. Saunders, 1972:474.

40 Roberts WC. The congenitally bicuspid aortic valve. A stud of 85 autopsy cases. Am $\mathcal{F}$ Cardiol 1970;26:72-83.

41 Fisher RD, Mason DT, Morrow AG. Results of operative treatment in congenital aortic stenosis. Pre- and postoperative haemodynamic evaluations. F Thorac Cardiovasc Surg 1970;59:218-24.

42 Kirklin JW, Barratt Boyes BG. Cardiac Surgery. New York Wiley Medical Publications, 1986:972.

43 Bernhard WF, Keane JF, Fellows KE, Litwin SB, Gross RE. Progress and problems in the surgical management of Prongenital aortic stenosis. f Thorac Cardiovasc Surg 1973;66:404-19.

44 Sandor GGS, Olley PM, Trusler GA, Williams WG, Rowe $\mathrm{RD}$, Morch JE. Long-term follow up of patients afte valvotomy for congenital valvular aortic stenosis in children. A clinical and actuarial follow up. $f$ Thora Cardiovasc Surg 1980;80:171-6.

45 Gunning JF, Oakley CM. Aortic valve disease in Turner's syndrome. Lancet 1970;1:389-91.

46 Miller MJ, Geffner ME, Lippe BM, Itami RM, Kaplan SA DiSessa TG, Isabel-Jones JB, Friedman WF. Echocardiography reveals a high incidence of bicuspid aortic valve in Turner syndrome. $\mathcal{F}$ Paediatr 1983;102:47-50.

47 Wheller JJ, Hosier DM, Teske DW, Craenen JM, Kilman JW. Results of operation for aortic valve stenosis in infants, children and adolescents. $f$ Thorac Cardiovasc Surg 1988;96:474-7.

48 Selzer A. Changing aspects of the natural history of valvula aortic stenosis. $N$ Engl f Med 1987;317:91-8.

49 Sullivan ID, Wren C, Bain H, Hunter S, Rees PG, Taylo JFN, Bull C, Deanfield JE. Balloon dilatation of the aortic valve for congenital aortic stenosis in childhood. $\mathrm{Br}$ Hear 7 1989;61:186-91.

50 Rocchini AP, Beekman RH, Ben Shachar G, Benson I Schwartz D, Kan JS. Balloon aortic valvuloplasty: results of the valvuloplasty and angioplasty of congenital anomalies registry. Am F Cardiol 1990;65:784-9.

See Appendix 1 overleaf 


\section{Appendix I}

FREEDOM FROM DEATH (FIG 3)

(a) Shaping and scaling parameter estimates for survivorship and hazard function for death after presentation with aortic valve disease.

Two phases-early and constant-were resolved. The parameter estimates were as follows:

Early phase: $\mathrm{mu}_{1}=0 \cdot 1143681$, delta $=0$, rho $=1 \cdot 210791$, $\mathrm{nu}=1, \mathrm{~m}=2 \cdot 438447$.

Constant phase: $\mathrm{mu}_{2}=0.0005317111$.

(b) Equations, coefficients (SD) and $p$ values in the multivariate analysis of correlates of death after presentation.

Early Phase: delta $=0$, rho $=1 \cdot 116338$, nu $=1, \mathrm{~m}=$ $2 \cdot 114911$, intercept $=-4 \cdot 47879$, aortic stenosis gradient at presentation $1.350(0.29)(p \leqslant 0.0001)$, age at presentation (months, logarithmic transform) $-0.510(0.14)(\mathrm{p}=$ 0.0003).

Constant phase: intercept $=-11 \cdot 677$, aortic stenosis grade at presentation $2.728(0.41)(p \leqslant 0.0001)$, presence of syndrome $2.204(0.95)(\mathrm{p}=0.021)$.

(c) Sequential increase in log likelihood (information content) as the incremental risk factors for death after presentation with aortic valve disease were assembled into the multivariate equation.

Total multivariate equation increment in log likelihood $=61.9$.
FREEDOM FROM FIRST EVENT (FIG 4)

(a) Shaping and scaling parameter estimates for survivorship and hazard function for first significant event after presentation with aortic valve disease.

Two phases early and constant were resolved. The parameter estimates were as follows:

Early phase: $\mathrm{mu}_{1}=0 \cdot 1257512$ delta $=0$, rho $=0.8317023$, $\mathrm{nu}=1, \mathrm{~m}=2 \cdot 587743$.

Constant phase: $\mathrm{mu}_{2}=0.02691725$.

(b) Equations, coefficients (SD) and $p$ values in the multivariate analysis of correlates for first significant event after presentation.

Early phase: delta $=0$, rho $=0.8013868, \mathrm{nu}=1, \mathrm{~m}=$ $2 \cdot 461427$, intercept $=-6.06944$, aortic stenosis grade at presentation (square transform) $0.564(0.09)$ ( $\mathrm{p} \leqslant$ 0.0001 ), age at presentation (months; negative reciprocal transform) $-0.112(0.03)(p \leqslant 0.0001)$, maleness 1.101 $(0.61)(\mathrm{p}=0.073)$.

Constant phase: Intercept $=-8 \cdot 704$, aortic stenosis grade at presentation $2.135(0.24)(\mathrm{p} \leqslant 0.0001)$, presence of significant associated cardiac lesions $0.633(0.24)(\mathrm{p}=$ 0.008).

(c) Sequential increase in log likelihood (information content) as the incremental risk factors for first significant event after presentation with aortic valve disease were assembled into the multivariate equation.

Total multivariate equation increment in log likelihood $=$ $86 \cdot 0$.

\begin{tabular}{|c|c|c|c|}
\hline Risk factor assembly & $\begin{array}{l}\text { Log } \\
\text { likelihood }\end{array}$ & $\begin{array}{l}\text { Total multi- } \\
\text { variate } \\
\text { equation } \\
\text { increment } \\
\text { in log } \\
\text { likelihood } \\
(\%)\end{array}$ & $\begin{array}{l}\text { Increase in } \\
\text { increment } \\
\text { provided } \\
\text { by new } \\
\text { variable } \\
\text { (\%) }\end{array}$ \\
\hline $\begin{array}{l}\text { Hazard function }(n=239) \\
\text { Aortic stenosis grade at presentation } \\
\text { (square transform; early phase) }\end{array}$ & $\begin{array}{l}-476 \cdot 7 \\
-425 \cdot 0\end{array}$ & $\begin{array}{l}\text { NA } \\
60 \cdot 2\end{array}$ & $\begin{array}{l}\text { NA } \\
60 \cdot 2\end{array}$ \\
\hline $\begin{array}{l}\text { Aortic stenosis grade at presentation } \\
\text { (constant phase) }\end{array}$ & $-400 \cdot 2$ & $89 \cdot 0$ & $28 \cdot 8$ \\
\hline $\begin{array}{l}\text { Age at presentation (mnth, logarithmic } \\
\text { transform) }\end{array}$ & $-394 \cdot 8$ & $95 \cdot 2$ & $6 \cdot 2$ \\
\hline $\begin{array}{l}\text { Presence of significant associated cardiac } \\
\text { lesions (constant phase) }\end{array}$ & $-392 \cdot 2$ & $98 \cdot 2$ & 3.0 \\
\hline Maleness (early phase) & $-390 \cdot 7$ & 100 & $1 \cdot 8$ \\
\hline
\end{tabular}

